\begin{tabular}{|c|c|c|}
\hline 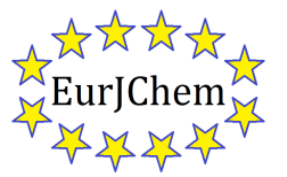 & $\begin{array}{c}\text { European Journal of Chemistry } \\
\text { Journal homepage: } \underline{w w w . e u r j c h e m . c o m ~}\end{array}$ & 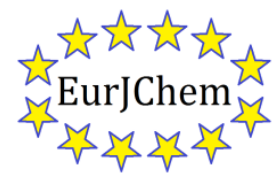 \\
\hline
\end{tabular}

\title{
Identification of degradation products in Aripiprazole tablets by LC-QToF mass spectrometry
}

\author{
Gosula Venkat Rami Reddya, Avvaru Praveen Kumarb, ${ }^{*}$, Bobba Venkateswara Reddya, Poonam kumara, \\ and Ham Dutt Gauttama
}

a Jubilant Organosys Limited, Noida, Utterpradesh, 201301, India

${ }^{b}$ Department of Chemistry, Yeungnam University, Gyeongsan, 712749, Korea

*Corresponding author at: Department of Chemistry, Yeungnam University, Gyeongsan, 712749, Korea. Tel.: +82.53.8102347; fax: +82.53.8104613. E-mail address: drkumar.kr@gmail.com (A. Praveen Kumar).

\section{ARTICLE INFORMATION}

Received: 15 February 2010

Received in revised form: 4 March 2010

Accepted: 10 March 2010

Online: 31 March 2010

\section{KEYWORDS}

\section{Aripiprazole}

Identification of degradation impurities

LC-QToF-MS

HPLC

\begin{abstract}
This paper describes the separation, identification and proposed structures of the degradation products formed during degradation analysis of aripiprazole in its final dosage form by high performance liquid chromatography (HPLC) coupled with quadrupole time-offlight mass spectrometry (QToF-MS). The drug product was subjected to stress conditions including acid, base, thermal, oxidation, humidity and photolytic degradations. Aripiprazole was found to be stable in all conditions except in thermal and peroxide degradations. The degradation impurities were first separated by HPLC and then identified using QToF mass spectrometry. QToF mass spectrometer provided high order of mass accuracy for unknown impurities and their fragment ions to explore the elemental composition. Based on the fragmentation pattern, the possible structures of the unknown impurities were proposed. To the best of our knowledge, there were no methods available to identify the impurities during degradation of aripiprazole tablets by liquid chromatography-mass spectrometry.
\end{abstract}

\section{Introduction}

Aripiprazole is chemically named as 7-[4-[4-(2,3dichlorophenyl)piperazin-1-yl]butoxy]-3,4-dihydro-1Hquinolin-2-one. It is a novel and a typical drug used for the treatment of schizophrenia which is the common and well recognized psychiatric disorder, stimulated by inordinate neurotransmission action of the dopaminergic nervous system in the central nervous system [1]. Aripiprazole is a selective monoaminergic antagonist with high affinity for the serotonin Type $2\left(5 \mathrm{HT}_{2}\right)$, dopamine Type $2\left(\mathrm{D}_{2}\right)[2], 1$ and 2 adrenergic and $\mathrm{H}_{1}$ histaminergic receptors [3,4]. It acts as an antagonist at other receptors but with lower potency. Antagonism at receptors other than dopamine and $5 \mathrm{HT}_{2}$ with similar receptor affinities may explain some of the other therapeutic and side effects of aripiprazole. It has been proved that the aripiprazole can improve both positive and negative symptoms in patients with schizophrenia and schizoaffective disorder in clinical studies [5-7].

In pharmaceutical industry, drug development demands several physical and chemical properties to be evaluated in the drug substance and formulations to satisfy the FDA and ICH regulations $[8,9]$. Among those properties, stability of the new drug is a significant factor, requiring elaborated analysis of potential degradation products [10]. The information regarding degradation products is commonly obtained by extended stability studies carried out under different conditions, such as exposure to adverse temperatures, hydrolysis, $\mathrm{pH}$, humidity, oxidation, etc. [9]. As per regulatory guidelines, the pharmaceutical studies using a sample of isolated impurities can be considered for safety assessment. It is, therefore, essential to isolate and characterize the un-identified impurities present in the drug sample. So, structural elucidation of unknown impurities is an analytical challenge that requires both selective and sensitive methods $[11,12]$.

Different analytical techniques have been reported for the determination of aripiprazole and its metabolites in human plasma by liquid chromatography-mass spectrometry (LC-MS) $[13,14]$, in blood samples of psychiatric patients by gas chromatography-mass spectrometry (GC-MS) [15] and in pharmaceutical dosage forms by liquid chromatography (LC) [16]. Zha et al. described a LC method for separation of impurities related to aripiprazole [17] and Sreenivas et al. reported degradation study of aripiprazole drug substance (active pharmaceutical ingredient) using LC [18].

Until today, no degradation study was available on aripiprazole using liquid chromatography-mass spectrometry (LC-MS). In the present work, degradation studies of aripiprazole drug product including thermal, oxidation, humidity, photolytic, acid and base were carried out using LCQToF-MS to identify the degradation products. MS and MS/MS studies were implemented for these products using QToF micromass instrument.

\section{Experimental}

\subsection{Chemicals and Reagents}

Reference standard of aripiprazole, aripiprazole tablets and five known impurities namely, 7-HDQ: 7-hydroxy-3,4dihydroquinolin-2(1H)-one. DCPP: 1-(2,3-dichlorophenyl)pipe razine hydrochloride. APR-I: 7-(4-bromobutoxy)-3,4-dihydro quinolin-2(1H)-one. Imp-B: 7,7'-(Butylenedioxy)di-3,4-dihydro quinolin-2(1H)-one. N-BDQ: 7-[4-[4-(2,3-Dichlorophenyl)pipe 
razin-1-yl]butoxy]-1-[4-(2-oxo-3,4-dihydro-1H-quinolin-7-yl) butoxy]-3,4-dihydro-1H-quinolin-2-one (Figure 1) were obtained from Jubilant Organosys Limited (Noida, India). LCMS grade methanol $(\mathrm{MeOH})$ and acetonitrile (ACN) were purchased from J. T. Baker (Mexico, USA). Analytical reagent grade sodium hydroxide was purchased from Ranchem (Ranbaxy laboratories Ltd, Gurgaon, India). Ultra pure water was obtained from a water purification unit (Elga Ltd., England). Ammonium acetate and formic acid were purchased from Sigma-Aldrich (Steinheim, Germany).<smiles>O=C1CCc2ccc(OCCCCCN3CCN(c4cccc(Cl)c4Cl)CC3)cc2N1</smiles><smiles>CCNc1cccc(Cl)c1</smiles>

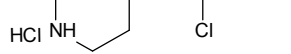

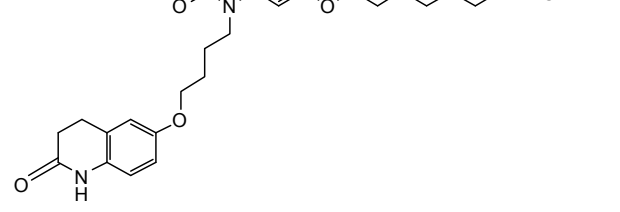

Figure 1. Structures of aripiprazole and its known impurities

\subsection{Equipment}

A Waters HPLC system of Alliance 2695 (Milford, MA, USA) was equipped with quaternary gradient pumps, auto-sampler and a photo diode array detector (PDA 2996). This HPLC system was connected to Waters QToF micro mass spectrometer (Milford, MA, USA) and operated with MassLynx software.

\subsection{Diluent}

Diluent was prepared by dissolving $4 \mathrm{~g}$ of sodium hydroxide in $100 \mathrm{~mL}$ water and then diluted to $1000 \mathrm{~mL}$ with $\mathrm{MeOH}$.

\subsection{Controlled sample preparation}

20 tablets of aripiprazole were crushed to a fine powder and an amount equivalent to $20 \mathrm{mg}$ of aripiprazole was transferred into a $100 \mathrm{~mL}$ volumetric flask, added $70 \mathrm{~mL}$ of diluent and then sonicated for 30 min with intermittent shaking. Finally, the volume of the sample was made up to 100 $\mathrm{mL}$ with diluent. Subsequently, the solution was filtered through a $0.45 \mu \mathrm{m}$ nylon membrane filter. Controlled sample was prepared to confirm the drug product does not have any degradation product.

\subsection{Preparation of spiked solution of impurities for mass confirmation}

Sample powder equivalent to $20 \mathrm{mg}$ of aripiprazole was transferred into a $100 \mathrm{~mL}$ volumetric flask and $2 \mu \mathrm{g}$ of each individual known impurity were added. Also, $70 \mathrm{~mL}$ of diluent was added, sonicated for $30 \mathrm{~min}$ with intermittent shaking and finally the volume was completed with diluent. Afterwards, the solution was filtered through a $0.45 \mu \mathrm{m}$ nylon membrane filter. The filtered solution was taken as impurities' spiked solution.

\subsection{Stress decomposition studies}

Acidic, alkaline and peroxide degradation studies were conducted by using $5 \mathrm{M} \mathrm{HCl}, 5 \mathrm{M} \mathrm{NaOH}$ and $5 \mathrm{~mL}$ of $30 \% \mathrm{H}_{2} \mathrm{O}_{2}$, respectively. All these studies were carried out at $70{ }^{\circ} \mathrm{C}$. Thermal, humidity and photolytic conditions were applied as per the Q1A (R2) ICH guidelines [19].

\subsection{Chromatographic conditions}

The mobile phase consists of a mixture of A and B; A was a buffer containing $2.54 \mathrm{~g}$ of ammonium acetate dissolved in $1000 \mathrm{~mL}$ water and its $\mathrm{pH}$ was adjusted to 2.5 with formic acid. $\mathrm{B}$ was $\mathrm{MeOH}: \mathrm{ACN}$ in the ratio of 50:50. The chromatographic separation was achieved on Symmetry C-18, 250 x $4.6 \mathrm{~mm}, 5$ $\mu \mathrm{m}$ column by performing gradient programme with a flow rate of $1.0 \mathrm{~mL} / \mathrm{min}$. The gradient programme performed for separation was shown in Table 1 . The detection wavelength was set at $248 \mathrm{~nm}$ and the injection volume was $10 \mu \mathrm{L}$.

\begin{tabular}{cccc}
\multicolumn{1}{l}{ Table 1. Gradient program. } \\
\hline Time & Flow & \%, A & \%, B \\
\hline 0.00 & 1.0 & 75 & 25 \\
40.0 & 1.0 & 40 & 60 \\
50.0 & 1.0 & 40 & 60 \\
55.0 & 1.0 & 75 & 25 \\
65.0 & 1.0 & 75 & 25 \\
\hline
\end{tabular}

\subsection{QToF mass spectrometric conditions}

For mass spectrometry detection, the parameters were tuned by injecting low concentrated aripiprazole standard for better mass sensitivity. QToF mass spectrometer was provided with electrospray ionization source and operating parameters were as follows: Capillary voltage, $3500 \mathrm{~V}$; sample cone voltage, $35 \mathrm{~V}$; extraction cone voltage, $2.0 \mathrm{~V}$. Collision energy was initially set at $5.0 \mathrm{eV}$ for MS experiments and varied from 5 to $30 \mathrm{eV}$ for MS/MS experiments. Nitrogen gas was used as nebulizer gas and Helium gas as collision gas. Nebulizer gas was supplied with a flow rate of $50 \mathrm{~L} / \mathrm{hr}$ and dry gas of 500 $\mathrm{L} / \mathrm{hr}$. In the time-of-flight analyzer, the flight tube voltage was set at $5630 \mathrm{~V}$ and the detector voltage was $2550 \mathrm{~V}$. All the experiments were carried out in the positive ionization mode.

\section{Results and Discussion}

\subsection{Development and optimization of LC method}

The optimum chromatographic resolution of aripiprazole and its degradation products was influenced by the $\mathrm{pH}$ of the aqueous phase (mobile phase $\mathrm{A}$ ), ratio of the organic modifier (mobile phase B) and the flow rate of the mobile phase. At the beginning, ammonium acetate buffer at $\mathrm{pH} 5.0$ was tried to separate all the known impurities and the degradants. It was found that the unknown impurity-1 formed in thermal 


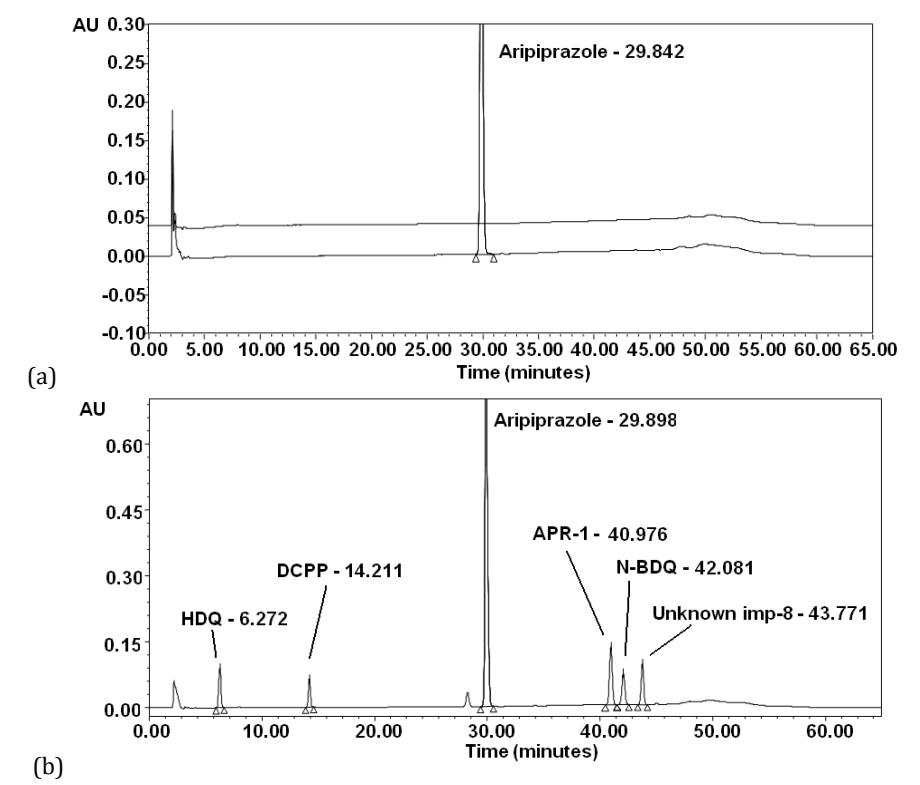

Figure 2. Chromatogram of control sample of aripiprazole tablet sample (a) and its impurities spiked solution (b)

degradation was merged with DCPP impurity and APR-1 impurity was eluted along with $N$-BDQ impurity. After changing the $\mathrm{pH}$ of the buffer to 3.5 , the unknown impurity-1 was still merged with the DCPP impurity. At $\mathrm{pH} 2.5$, all the known impurities and the degradants were well separated. Thus, pH 2.5 was selected for separation process.

To optimize the organic modifier, initially a $100 \% \mathrm{MeOH}$ was attempted. However, this $100 \% \mathrm{MeOH}$ was unable to elute non-polar impurities (APR-1 and $N$-BDQ). To elute these nonpolar impurities, mixtures of different ratios of ACN and $\mathrm{MeOH}$ have been used and lead to a better separation. The different flow rates from 0.8 to $1.3 \mathrm{~mL} / \mathrm{min}$ at the intervals of 0.1 $\mathrm{mL} / \mathrm{min}$ have been tried. Sharp peaks with good resolution were attained using $1.0 \mathrm{~mL} / \mathrm{min}$. A successful gradient run (mentioned in the experimental section) was employed to resolve all the known impurities and the degradation products which were formed during degradation. The optimized injection volume and detection wavelength were $10 \mu \mathrm{L}$ and $248 \mathrm{~nm}$, respectively.

\subsection{Degradation behavior}

The developed LC-MS method was used to study degradation behavior of aripiprazole in its tablet formulations under various stress conditions such as thermal, humidity, photolytic, acidic, basic and oxidation conditions. The control sample of aripiprazole showed only one major peak, a typical chromatogram of control tablet sample was shown in Figure 2a. The separation of aripiprazole from its known impurities (spiked solution of known impurities) was shown in Figure $2 \mathrm{~b}$ and it can ensure that the separation was achieved within 45 mins.

\subsection{Thermal degradation}

Thermal degradation was carried out by the exposure of aripiprazole tablet powder at $105^{\circ} \mathrm{C}$ for five days. Three major degradation products were observed within 3 days at relative retention times (RRT) of $0.45,1.06$ and $1.14 \mathrm{~min}$ and the corresponding chromatogram is shown in Figure 3a. No other new degradants were formed between 3-5 days.

\subsection{Oxidative degradation}

The oxidative degradation was performed using $30 \% \mathrm{H}_{2} \mathrm{O}_{2}$. Aripiprazole undergoes oxidative degradation and forms an unknown impurity at RRT 1.06 in major quantities (Figure 3b).

\subsection{Humidity degradation}

The aripiprazole tablet powder was exposed to $90 \%$ of relative humidity at room temperature up to 7 days. It has been observed that there was no significant degradation occurred (Figure 3c).

\subsection{Photolytic degradation}

The photolytic conditions such as 1.2 million lux hours and $200 \mathrm{Whrs} / \mathrm{m}^{2}$ were applied to aripiprazole tablets for five days. No degradation was observed and the represented chromatogram was shown in Figure 3d.

\subsection{Acid and base degradations}

The acid and base degradation studies were carried out by adding $5 \mathrm{~mL}$ of $5 \mathrm{M} \mathrm{HCl}$ and $5 \mathrm{M} \mathrm{NaOH}$, respectively. The aripiprazole was found to be stable under these conditions and respective chromatograms were shown in Figure 3e and 3f, respectively. The degradation studies reveal that the aripiprazole was undergone degradation in thermal and peroxide conditions. Under these degradation conditions, aripiprazole was degraded up to $30 \%$ and $10 \%$, respectively. In peroxide degradation, one degradation impurity formed at RRT 1.06 was also observed in thermal degradation. The major degradation impurities were detected in thermal condition within 3 days of the aripiprazole tablet formulation. No other new degradants were formed after 3 days.

\subsection{Mass accuracy}

The difference between theoretical and experimental masses is generally expressed in terms of mass accuracy. The accurate mass measurement gives the elemental composition of the parent and fragment ions and was used to identify unknown species. QToF-MS permits MS/MS analysis and provides accurate masses for both precursor and product ions, 


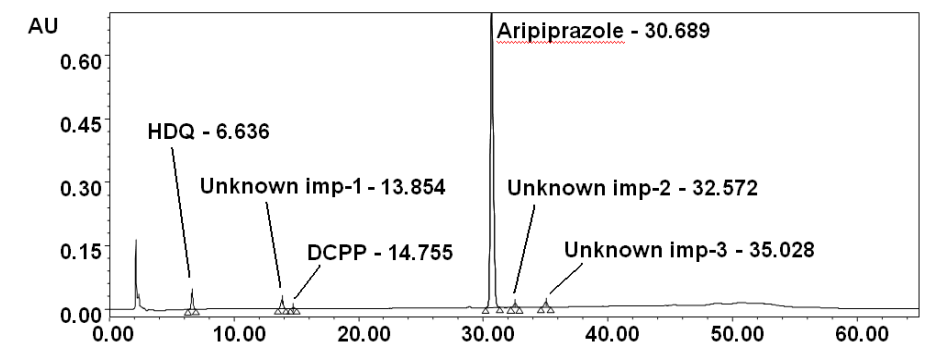

(a)

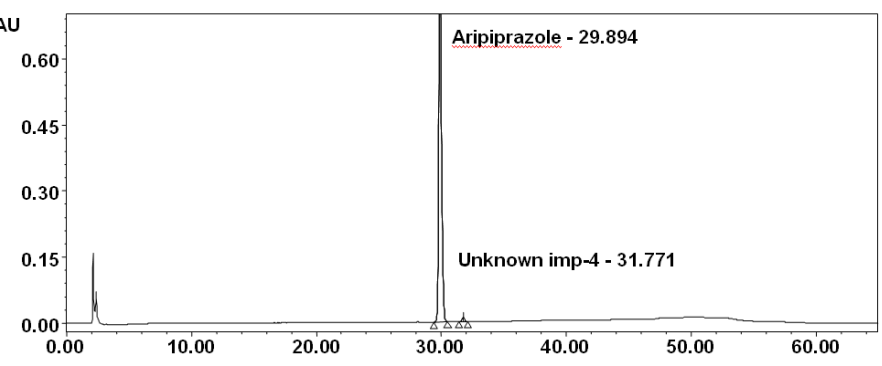

(b)

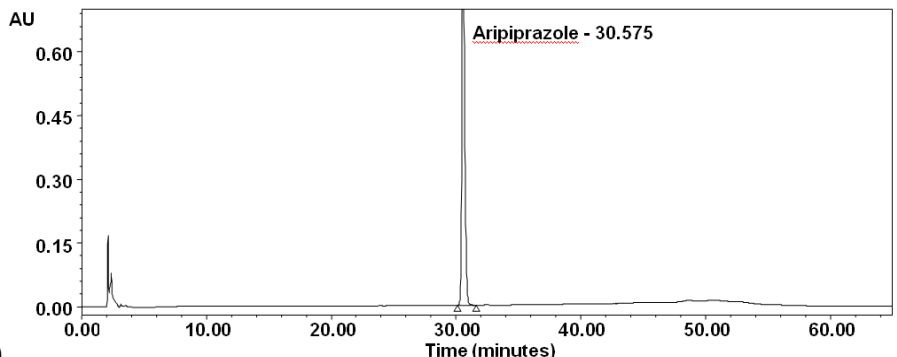

(c)

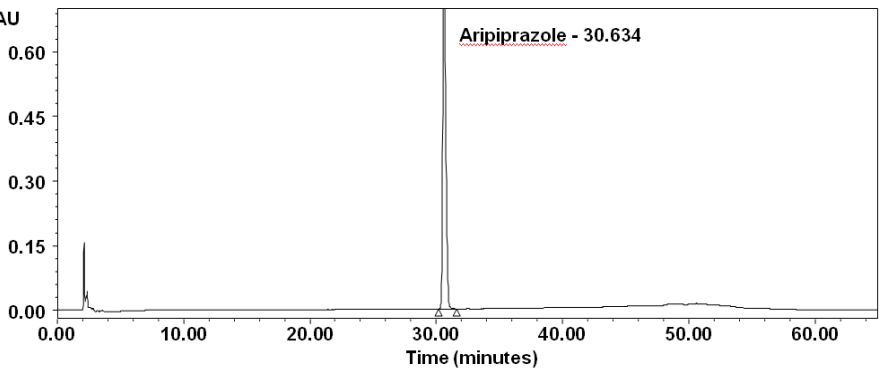

(d)

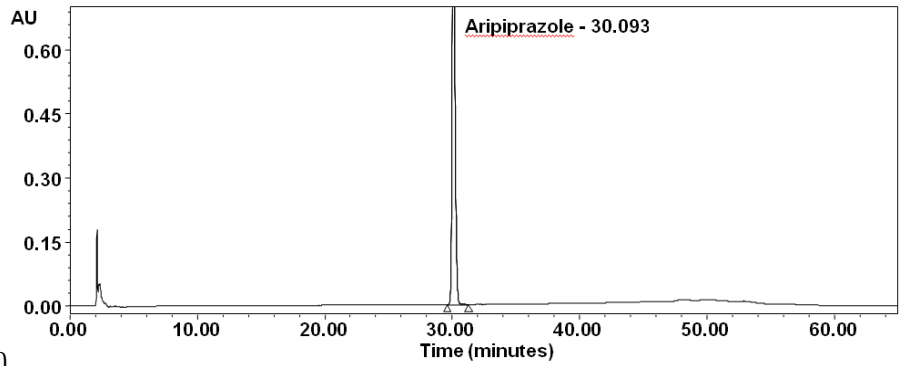

(e)

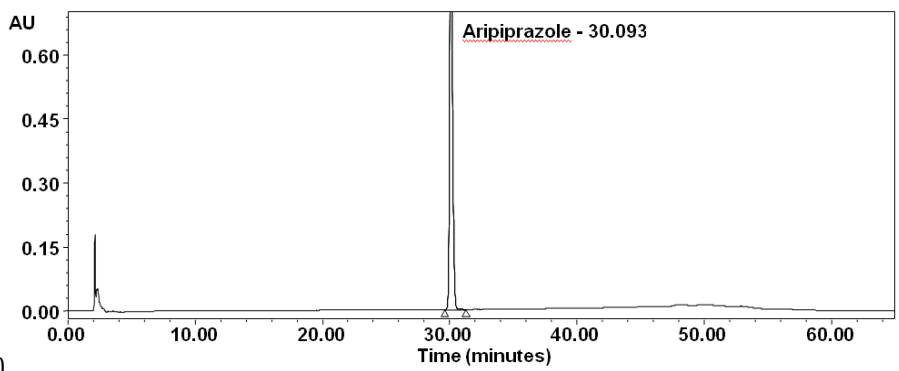

Figure 3. Thermal (a), peroxide (b), humidity (c), photolytic (d), acid (e) and base (f) degradation chromatograms of aripiprazole tablet sample. 
Table 2. Elemental composition and accurate mass measurement of precursor ions of aripiprazole and its unknown impurities in the mass spectrum of thermal degradation sample.

\begin{tabular}{lllllll}
\hline Product & RRT & Elemental Composition & Theoretical Mass $(\boldsymbol{m} / \mathbf{z})$ & Experimental Mass (m/z) & Mass Difference & Error (ppm) \\
\hline Aripiprazole & 1.00 & $\mathrm{C}_{23} \mathrm{H}_{28} \mathrm{CL}_{2} \mathrm{~N}_{3} \mathrm{O}_{2}$ & 448.1559 & 448.1557 & 0.4 \\
Unknown IMP-1 & 0.45 & $\mathrm{C}_{14} \mathrm{H}_{19} \mathrm{CL}_{2} \mathrm{~N}_{2}$ & 285.0925 & 285.0921 & 0.002 \\
Unknown IMP-2 & 1.06 & $\mathrm{C}_{23} \mathrm{H}_{28} \mathrm{CL}_{2} \mathrm{~N}_{3} \mathrm{O}_{3}$ & 464.1429 & 464.1427 & 0.0004 \\
Unknown IMP-3 & 1.14 & $\mathrm{C}_{13} \mathrm{H}_{16} \mathrm{NO}_{2}$ & 218.1181 & 218.1182 & 0.0002 \\
\hline
\end{tabular}

Table 3. RTs, RRTs and masses for molecular ion peaks of known and unknown impurities and their major fragments.

\begin{tabular}{|c|c|c|c|c|}
\hline Compound & RT(min) & RRT & Molecular ions & MS/MS Fragments \\
\hline Aripiprazole ${ }^{a}$ & 31.24 & 1.00 & $448[\mathrm{M}+\mathrm{H}]^{+}$ & $285,218,176$ \\
\hline 7-HDQ & 15.34 & 0.21 & $164[\mathrm{M}+\mathrm{H}]^{+}$ & $146,122,110$ \\
\hline DCPPa & 6.729 & 0.49 & $231[\mathrm{M}+\mathrm{H}]^{+}$ & 188,153 \\
\hline Imp-Ba & 42.20 & 1.35 & $403[\mathrm{M}+\mathrm{Na}]^{+}$ & $218,176,164$ \\
\hline APR-Ia & 43.61 & 1.39 & $298[\mathrm{M}+\mathrm{H}]^{+}$ & $218,176,164$ \\
\hline$N-\mathrm{BDQ}^{\mathrm{a}}$ & 45.08 & 1.44 & $665[\mathrm{M}+\mathrm{H}]^{+}$ & 285 \\
\hline Unknown imp-1b & 13.854 & 0.45 & $285[\mathrm{M}+\mathrm{H}]^{+}$ & $231,188,154$ \\
\hline Unknown imp-2b & 32.572 & 1.06 & $464[\mathrm{M}+\mathrm{H}]^{+}$ & $285,218,176,164$ \\
\hline Unknown imp-3b & 35.028 & 1.14 & $218[\mathrm{M}+\mathrm{H}]^{+}$ & $176,164,146$ \\
\hline
\end{tabular}

a Known impurities at $1.0 \%$ level spiked solution

b Unknown impurities under thermal degradation.

which constitutes a higher order mass identification than those afforded by nominal mass measurements obtained by other types of mass analyzers [20]. In QToF, the selectivity of precursor ion scans is very high because the high resolving power of the reflectron-ToF mass analyzers provides high accuracy fragment ions without compromising sensitivity [21]. The elemental composition was a complement from the interpreted fragmentation pattern and the accurate mass measurement of the obtained product ions, thus relieving existing equivocalnesses.

Mass measurement accuracy along with characteristic retention time, usually provides highly reliable identification of target species [22]. Table 2 lists the mass accuracies obtained in the mass measurement of the protonated molecule of aripiprazole and its unknown impurities. The mass error obtained for all unknown impurities including aripiprazole (precursor ions) was in the range of 0.4-1.4 ppm. This was less than the widely accepted accuracy threshold of $5 \mathrm{ppm}$ [23]. In accordance with experimental data, the best mass accuracy was obtained. The accurate mass measurements of aripiprazole and its unknown impurities were obtained from thermal degradation sample using the QToF-MS/MS at the optimized collision energy.

\subsection{Identification of the known and unknown impurities by QTOF-MS}

To confirm the known impurities retention times (RT), RRTs and their molecular ion peaks, each and every known impurity was spiked at $1.0 \%$ level to the aripiprazole drug product and the analysis was carried out. Figure $2 \mathrm{~b}$ presents the chromatogram showing the separation of aripiprazole from its known impurities and the respective data including MS were presented in Table 3. The collision induced dissociation energy was optimized for every known impurity in QToF mass spectrometer to get the major fragments. The $m / z$ values corresponding to molecular ion peaks and their MS/MS fragments contributed in the confirmation of the known impurities.

Figure 3a shows the chromatograms of the aripiprazole tablet sample under the thermal degradation condition, the unknown impurities were detected at RRTs of $0.45,1.06$ and 1.14 with respect to aripiprazole RT. Table 3 describes the RTs, RRTs, $m / z$ values of molecular ion peaks and their major fragment ions corresponding to the unknown impurities (degradation products). Based on RRTs and $m / z$ values of molecular ion peaks, the existence of three unknown impurities can be confirmed. In thermal degradation condition, the aripiprazole tablet sample undergone major degradation and three unknown impurities were detected.

\subsection{Structural elucidation of the unknown impurities}

From the degradation studies, three unknown impurities were identified at RRTs $0.451,1.061$ and 1.141 with respect to aripiprazole RT. The fragmentation pattern of the aripiprazole could give some information regarding the structural elucidation of the unknown impurities. The MS and MS/MS spectra of aripiprazole were presented in Figure 4. Three important fragments were observed from aripiprazole MS/MS spectrum and were at $\mathrm{m} / \mathrm{z}$ values of 285,218 and 176 . The $\mathrm{m} / \mathrm{z}$ at 285 was due to the loss of 7-hydroxyquinol moiety from the aripiprazole and $\mathrm{m} / \mathrm{z}$ at 218 was due to the lack of dichlorophenyl piperazine ring. The fragment at $\mathrm{m} / \mathrm{z} 176$ was obtained by the removal of 1-(2,3-dichlorophenyl)-4-propyl piperzine moiety. The fragmentation pattern of aripiprazole was presented in Scheme 1.

Figure 5 shows MS and MS/MS spectra of the unknown impurity at RRT 0.45 from thermal degradation of aripiprazole tablet sample. In the MS spectrum of this unknown impurity, dichloro isotopic peaks were observed at $\mathrm{m} / \mathrm{z} 285$ and 287 having the intensity in the ratio of $3: 2$, which proves that this

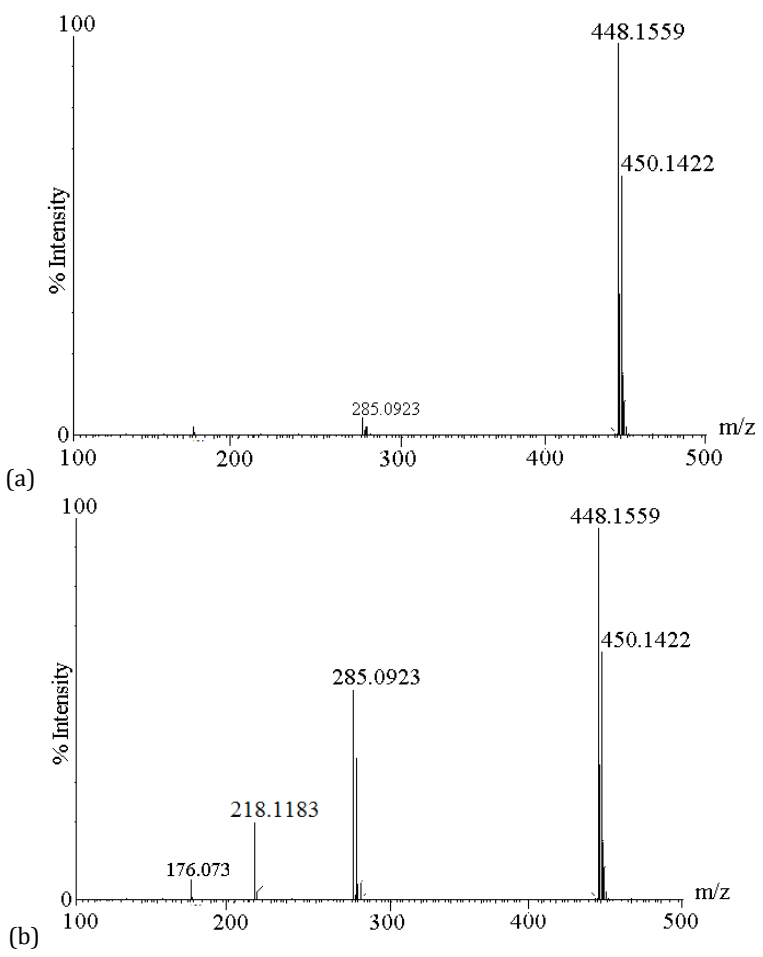

Figure 4. MS (a) and MS/MS (b) spectra of the aripiprazole 
degradation impurity possess two chlorine atoms in its structure. The major fragments of this unknown impurity observed were at $m / z 231,188$ and 154 . The fragments at $m / z$ 231 was obtained due to loss of 1 -butene, $m / z 188$ was due to loss of $N, N$-dimethyl-1-butene and $m / z 154$ was due to lack of $N, N$-dimethyl-1-butene along with chlorine. The fragmentation pattern of this unknown impurity and its possible structure were presented in Scheme 2.

The peak at RRT 1.06 showed the molecular ion at $m / z 464$ in the MS spectrum of thermal degradation sample (Figure 6a). This molecular ion mass was 16 mass units higher than that of aripiprazole and this indicates that the probability to the formation of $\mathrm{N}$-oxide. The same impurity was also observed in oxidative degradation, but in smaller quantities. Figure $6 \mathrm{~b}$ presents the MS/MS spectrum of this unknown impurity from
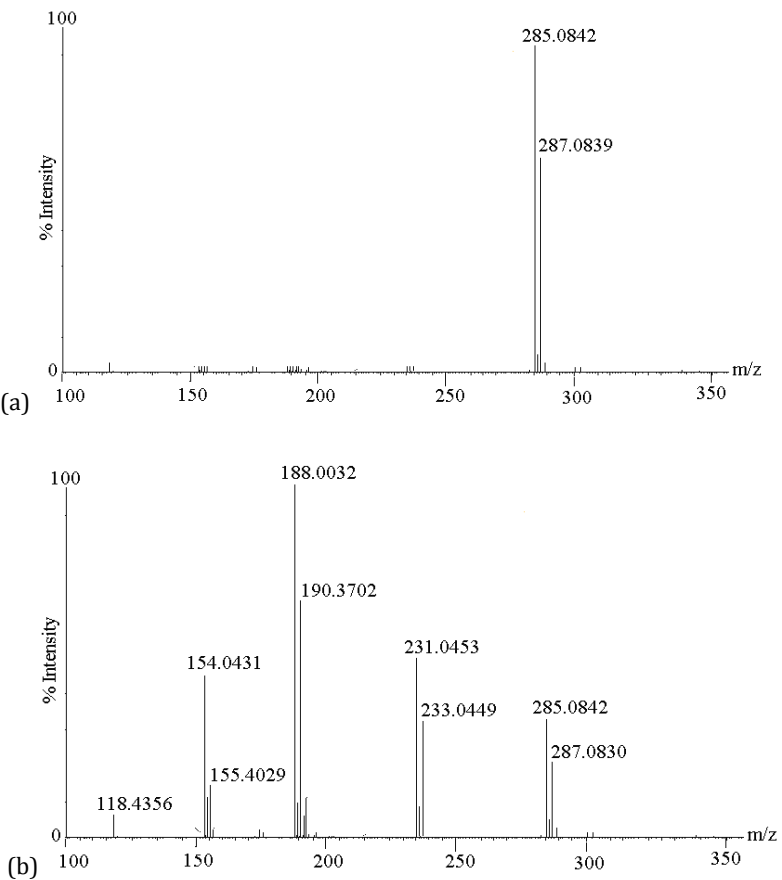

Figure 5. MS (a) and MS/MS (b) spectra of the unknown impurity at RRT 0.45 in thermal degradation of aripiprazole tablet sample.<smiles>[CH2+]CCCOc1ccc2c(c1)NC(=O)CC2</smiles>

$m / z 218.1181$<smiles>O=C1CCc2ccc(OCCCCN3CCN(/C=C(\Cl)CCl)CC3)cc2N1</smiles><smiles>CCCN1CCN(C2CCCC2Cl)CC1</smiles><smiles>[CH2+]Oc1ccc2c(c1)NC(=O)CC2</smiles>

$m / z 176.0711$

Scheme 1. Fragmentation of aripiprazole.

thermal degradation sample of aripiprazole tablet. In aripiprazole, there were three nitrogen atoms, but the $N$-oxide formation takes place at the piperazine ring [24] and was proved by MS/MS study of this impurity. The main fragments of this unknown impurity were detected at $\mathrm{m} / \mathrm{z}$ values of 285 , $243,218,178$ and 164. The fragmentation pattern of this unknown impurity and its possible structure were presented in Scheme 3 .<smiles>Clc1cccc(N2CCNCC2)c1Cl</smiles>

$\mathrm{m} / \mathrm{z} 231.0456$<smiles>C=CCCN(C)CC[N+]1(CCC=C)CCN(c2cccc(Cl)c2Cl)CC1</smiles><smiles>CN(C)c1ccccc1Cl</smiles>

$m / z 154.0424$

Scheme 2. Fragmentation of the unknown impurity at RRT 0.45 .

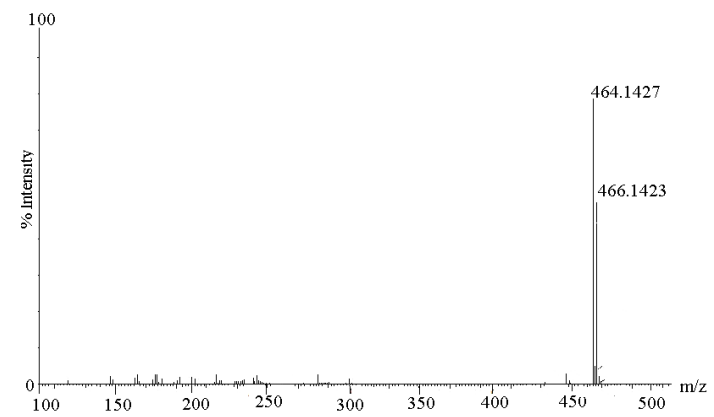

(a)

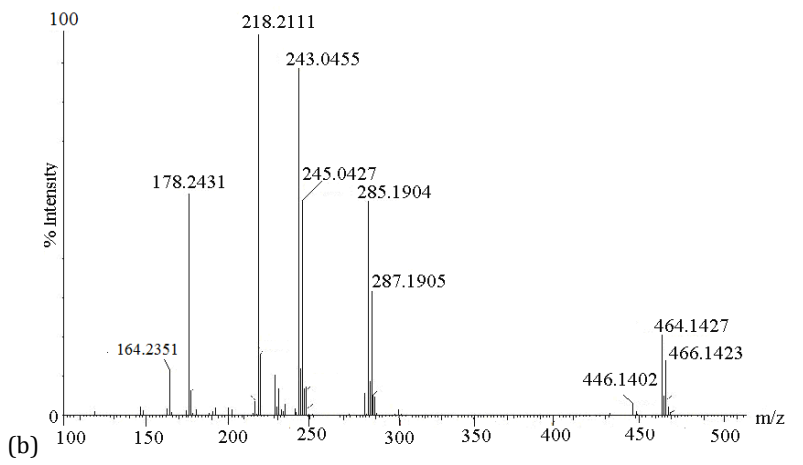

Figure 6. MS (a) and MS/MS (b) spectra of the unknown impurity at RRT 1.06 in thermal degradation of aripiprazole tablet sample. 
Figure 7 shows the MS and MS/MS spectra of the unknown impurity at RRT 1.14 in thermal degradation of aripiprazole tablet sample. The unknown impurity having the molecular ion at $m / z 218$ and its major fragments were observed at $m / z 176$, 164 and 146. This impurity was found in the aripiprazole moiety, indicates that the moiety was coming from the aripiprazole. The MS spectrum of this unknown impurity suggests that it did not have the chloro moiety. The fragmentation pattern and the possible structure of this unknown impurity were presented in Scheme 4.

(a)
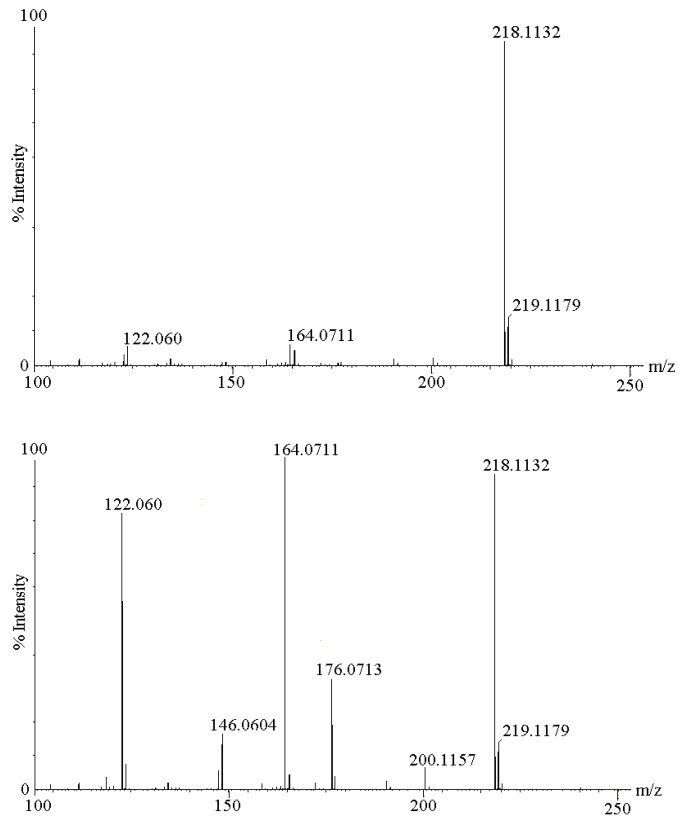

(b)

Figure 7. MS (a) and MS/MS (b) spectra of the unknown impurity at RRT 1.14 in thermal degradation of aripiprazole tablet sample.

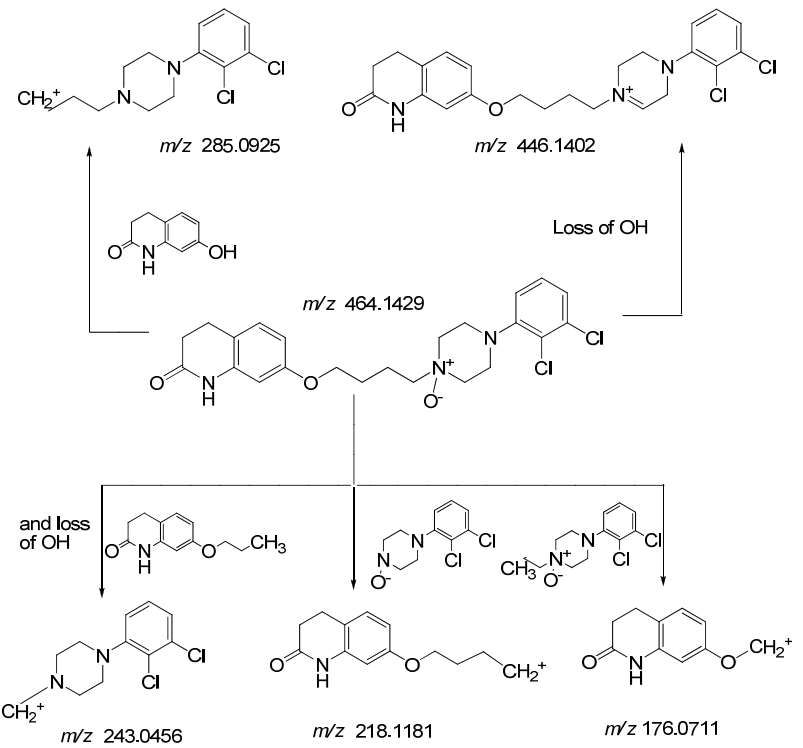

Scheme 3. Fragmentation of the unknown impurity at RRT 1.06 .

\section{Conclusions}

This investigation demonstrated the unambiguous identification of the unknown impurities formed during degradation studies of aripiprazole tablets and was achieved by
LC-QToF-MS. Aripiprazole tablet formulation undergoes severe degradation in thermal degradation condition of $105^{\circ} \mathrm{C}$ for 3 days. Three unknown impurities at RRTs of $0.45,1.06$ and 1.1.4 were detected during the degradation studies. From QToF-MS and MS/MS fragmentation pattern, the structures of the unknown impurities in aripiprazole drug product were elucidated and named as 1-but-3-enyl-4-(2,3-dichloro-phenyl)piperazine (0.45 RRT), aripiprazole $N$-oxide (1.06 RRT) and 7but-3-enyloxy-3,4-dihydro-1H-quinolin-2-one (1.14 RRT). Finally, QToF mass study is a useful technique for structure elucidation of the unknown impurities in the aripiprazole tablets.

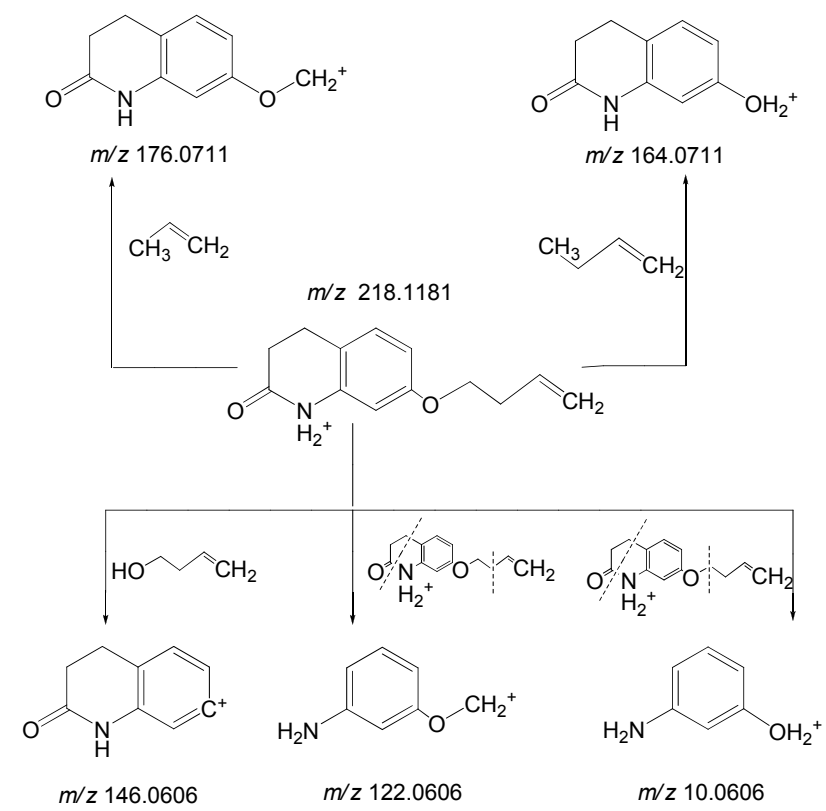

Scheme 4. Fragmentation of the unknown impurity at RRT 1.14 .

\section{Acknowledgement}

The authors wish to thank Jubilant Organosys (Noida, India), Mrs. Poonam Kumar and H. D. Gauttam for their support to provide the samples and encouragement.

\section{References}

[1]. Tamminga, C. A. J. Neural Transm. 2002, 109, 411-420.

[2]. Burris, K. D.; Molski, T. F.; Xu, C.; Ryan, E.; Tottori, K.; Kikuchi, T.; Yocca, F. D.; Molinoff, P. B. J. Pharmacol. Exp. Ther. 2002, 302, 381389.

[3]. Jordan, S.; Koprivica, V.; Chen, R.; Tottori, K.; Kikuchi, T.; Altar, C.A. Eur. J. Pharmacol. 2002, 441, 137-140.

[4]. Hirose, T.; Uwahodo, Y.; Yamada, S.; Miwa, T.; Kikuchi, T.; Kitagawa, H.; Burris, K. D.; Altar, C. A.; Nabeshima, T. J. Psychopharmacol. 2004, 18 375-383.

[5]. Kane, J. M.; Carson, W. H.; Saha, A. R.; McQuade, R. D.; Ingenito, G. G. Zimbroff, D. L.; Ali, M. W. J. Clin. Psychiatry 2002, 63, 763-771.

[6]. Potkin, S. G.; Saha, A. R.; Kujawa, M. J.; Carson, W. H.; Ali, M.; Stock, E.; Stringfellow, J.; Ingenito, G.; Marder, S. R. Arch. Gen. Psychiatry 2003, 60, 681-690.

[7]. Kasper, S.; Lerman, M. N.; McQuade, R. D.; Saha, A.; Carson, W. H.; Ali, M.; Archibald, D.; Ingenito, G.; Marcus, R.; Pigott, T. Int. J. Neuropsychopharmacol. 2003, 6, 325-337.

[8]. Ribeiro, Y. A.; de Oliveira, J. D. S.; Leles, M. I. G.; Juiz, S. A.; Ionashiro, M. J. Therm. Anal. 1996, 46, 1645-1655.

[9]. Zhou, W.; Gilpin, R. K. J. Pharm. Sci. 2004, 93, 1545-1556.

[10]. Berridge, J. C. J. Pharm. Biomed. Anal. 1995, 14, 7-12.

[11]. Branch, S.K. J. Pharm. Biomed. Anal. 2005, 38, 798-805.

[12]. Roy, J. AAPS PharmSciTech 2002, 3, 1-8.

[13]. Zuo, X. C.; Wang, F.; Xu, P.; Zhu, R. H.; Li, H. D. Chromatographia, 2006, 64, 387-391. 
[14]. Masanori, K.; Yasuo, M.; Yukihiro, H.; Takahiko, O. J. Chromatogr. B 2005, 822, 294-299.

[15]. Hui-Ching, H.; Chin-Hung, L.; Tsuo-Hung, L.; Tsung-Ming, H.; HsienJane, C.; Yu-Chun, W.; Ying Lung, T. J. Chromatogr. B, 2007, 856, 57-61.

[16]. Shah, V. P.; Kamal, K. M.; Shrikant, D.; Iain, J. M.; Jerome, P. S.; Avraham, Y.; Thomas, L.; Viswanathan, C. T.; Edgar, C.; McDowall, R. D.; Kenneth, A. P.; Sidney, S. J. Pharm. Sci. 1992, 81, 309-312.

[17]. Zha, J. P., Xu, H. J., Wang, Y. Z., Yang, S. G., Jia, C. X., Hou, Z. F. Chin. Pharm. J. 2005, 40, 137-139.

[18]. Srinivas, K. S. V.; Buchireddy, R.; Madhusudhan, G.; Mukkanti, K.; Srinivasulu, P. Chromatographia 2008, 68, 635-640.

[19]. ICH Topic Q1A (R2) 2003 Stability Testing of new Drug Substances and Products, CPMP/ICH/2736/99.

[20]. Lacorte, S.; Fernandez-Alba, A. R. Mass Spectrom. Rev. 2006, 25, 866880.

[21]. Schmid, R. P.; Weickhardt, C. Int. J. Mass Spectrom. 2001, 206, 181190.

[22]. Ferrer, I.; García-Reyes, J. F.; Fernandez-Alba, A. Trends in Anal. Chem. 2005, 24, 2005.

[23]. Petrovic, M.; Gros, M.; Barcelo, D. J. Chromatogr. A 2006, 1124, 68-81.

[24]. (WO/2003/064393) Thio-carbostyril derivative, its $N$-oxides and the $\mathrm{N}$-oxides of aripiprazole. 